Gut and Liver, Vol. 10, No. 1, January 2016, pp. 6-7

\title{
Do Esophageal Squamous Cell Carcinoma Patients Have an Increased Risk of Coexisting Colorectal Neoplasms?
}

\author{
Byung Ik Jang and Moon Joo Hwang \\ Department of Internal Medicine, Yeungnam University College of Medicine, Daegu, Korea
}

See "Esophageal Squamous Cell Carcinoma Patients Have an Increased Risk of Coexisting Colorectal Neoplasms" by Myong Ki Baeg, et al. on page 76, Vol. 10. No. 1, 2016

The frequency of esophageal cancer is globally on the increase. Esophageal cancer is a relatively rare type of cancer in Korea: its incidence and prevalence rates are 3.1 and 6.4, respectively, out of 100,000 persons. Esophageal squamous cell carcinoma (ESCC) has been regarded as a type of cancer with a poor survival rate and is characterized by the ninth highest mortality rate among all the types of cancer. As the early diagnosis using esophagogastroduodenoscopy and technological development, which involves image enhancement and endoscopy using iodine dye, make a larger number of esophageal cancer patients diagnosed early and as the development of therapeutic protocols improves the long-term survival rate, the prevalence of esophageal cancer is on the increase. As a result, secondary primary malignancy (SPM) in esophageal cancer patients has attracted attention and a few relevant studies were conducted. ${ }^{1-3}$ Esophageal cancer patients may often have SPM in the head and neck, stomach and rarely have it in the colon, the lungs, the kidneys, and the female breasts. ${ }^{1}$ SPM, which accompanies esophageal cancer, shares risk factors with the cancer. Risk factors for ESCC usually include smoking (ESCC, 3 to 7 fold; adenocarcinoma, 2 fold risk), excessive alcohol intake ( $\geq 3$ drinks/ day), diet, achalasia, and low socioeconomic status; of these, the first two seem to be significant risk factors. ${ }^{4}$ It is widely known that head and neck cancer, a typical type of SPM, shares major risk factors with ESCC and frequently accompanies it. ${ }^{5}$

Esophageal cancer and colorectal neoplasm (CRN) also share some risk factors and colorectal cancer reportedly forms approximately $7 \%$ to $16 \%$ of all the types of SPM for esophageal cancer. ${ }^{2,6}$ While a few researchers have reported that Barrett's metaplasia or esophageal adenocarcinoma patients are at higher risk of CRN, there are relatively fewer studies on the correlation between ESCC and CRN. The meta-analysis performed by Andrici et al. ${ }^{7}$ showed that Barrett's metaplasia almost doubled the risk of colon polyp and colorectal cancer. Bollschweiler et al., ${ }^{8}$ who conducted a case-control study in a total of 171 esophageal cancer patients (78 adenocarcinoma and 93 ESCC), found that ESCC was relatively less correlated with CRN than adenocarcinoma: the ESCC and adenocarcinoma groups showed approximately 2-fold and 4.35-fold higher prevalence of CRN, respectively, than the control group. In contrast, colonoscopic evaluation in ESCC patients, which was restrictively conducted, obtained conflicting results. ${ }^{8-11}$

Recently, Baeg et al. ${ }^{12}$ performed retrospective analysis to determine correlation between ESCC and CRN. He compared 60 patients, who were recently diagnosed with ESCC and received colonoscopy within a year after the diagnosis, with 180 persons in the control group with age, gender, and body mass index matched. As a result, a significantly higher percentage of the ESCC group had CRNs (odds ratio [OR], 2.311; 95\% confidence interval [CI], 1.265 to 4.220) or advanced CRNs (OR, 2.317; 95\% CI, 1.185 to 4.530$)$. Multivariate analysis showed that the significant risk factors for CRN and advanced CRN were ESCC (OR, 2.157; 95\% CI, 1.106 to 4.070; $p=0.024$ ) and older age (OR, 1.068; $95 \% \mathrm{CI}, 1.032$ to 1.106 ; $\mathrm{p}<0.001)$. On the basis of these results, it is necessary to consider performing colonoscopy in case of ESCC diagnosis because ESCC patients may see a significant increase in the CRN and advanced CRN rates.

Although this study found that smoking was not a potential risk factor for CRN, it was likely to act as a confounding factor because the ESCC group had a significantly higher propor-

Correspondence to: Byung Ik Jang

Department of Internal Medicine, Yeungnam University College of Medicine, 170 Hyeonchung-ro, Nam-gu, Daegu 42415, Korea

Tel: +82-53-620-3830, Fax: +82-53-654-8386, E-mail: jbi@med.yu.ac.kr pISSN 1976-2283 eISSN 2005-1212 http://dx.doi.org/10.5009/gnl15564

@) This is an Open Access article distributed under the terms of the Creative Commons Attribution Non-Commercial License (http://creativecommons.org/licenses/by-nc/4.0) which permits unrestricted non-commercial use, distribution, and reproduction in any medium, provided the original work is properly cited. 
tion of patients with smoking history than the control group. Besides, as a retrospective study, it rarely provides accurate baseline information about significant risk factors for ESCC and colorectal cancer, such as smoking and alcohol intake. Multivariate analysis found no risk factor for CRN in the ESCC group. This is probably because it, as a single-center study, was conducted in a small sample. The CRN rate was $\geq 60 \%$ in the ESCC group and $>40 \%$ in the control group; CRNs could have been overestimated in the former group since the adenoma detection rate is generally about $20 \%$ to $25 \%$. It is therefore necessary to conduct multicenter, prospective research in a larger number of patients.

Despite these limitations, colonoscopy is expected to be applicable right after diagnosis of esophageal cancer in clinical practice, as recommended on the basis of these results. Taking unfavorable prognoses of esophageal cancer into account, however, it is necessary to conduct a well-designed, randomized prospective study to see if this will improve prognoses for esophageal cancer patients in the long term and care should be taken to determine a specific group of patients and a specific clinical stage in which colonoscopic screening is useful.

\section{CONFLICTS OF INTEREST}

No potential conflict of interest relevant to this article was reported.

\section{REFERENCES}

1. Nandy N, Dasanu CA. Incidence of second primary malignancies in patients with esophageal cancer: a comprehensive review. Curr Med Res Opin 2013;29:1055-1065.

2. Poon RT, Law SY, Chu KM, Branicki FJ, Wong J. Multiple primary cancers in esophageal squamous cell carcinoma: incidence and implications. Ann Thorac Surg 1998;65:1529-1534.

3. Chuang SC, Hashibe M, Scelo G, et al. Risk of second primary cancer among esophageal cancer patients: a pooled analysis of 13 cancer registries. Cancer Epidemiol Biomarkers Prev 2008;17:15431549.

4. Wynder EL, Dodo H, Bloch DA, Gantt RC, Moore OS. Epidemiologic investigation of multiple primary cancer of the upper alimentary and respiratory tracts: I. a retrospective study. Cancer 1969;24:730-739.

5. Goldstein HM, Zornoza J. Association of squamous cell carcinoma of the head and neck with cancer of the esophagus. AJR Am J Roentgenol 1978;131:791-794.

6. Natsugoe S, Matsumoto M, Okumura H, et al. Multiple primary carcinomas with esophageal squamous cell cancer: clinicopathologic outcome. World J Surg 2005;29:46-49.

7. Andrici J, Tio M, Cox MR, Eslick GD. Meta-analysis: Barrett's oesophagus and the risk of colonic tumours. Aliment Pharmacol Ther 2013;37:401-410.

8. Bollschweiler E, Schloesser T, Leers J, Vallböhmer D, Schäfer H, Hölscher AH. High prevalence of colonic polyps in white males with esophageal adenocarcinoma. Dis Colon Rectum 2009;52:299304.

9. Kuwano H, Nozoe T, Sumiyoshi K, et al. Oesophageal cancer coexisting with colorectal lesions. Eur J Surg 1996;162:797-800.

10. Miyazaki T, Tanaka N, Sano A, et al. Clinical significance of total colonoscopy for screening of colon lesions in patients with esophageal cancer. Anticancer Res 2013;33:5113-5117.

11. Leers JM, Schröder W, Vivaldi C, Gutschow C, Schäfer H, Hölscher $\mathrm{AH}$. Preoperative colonoscopy before esophagectomy and reconstruction with gastric interposition. Chirurg 2004;75:1210-1214.

12. Baeg MK, Choi MG, Jung YD, et al. Esophageal squamous cell carcinoma patients have an increased risk of coexisting colorectal neoplasms. Gut Liver 2016;10:76-82. 